\title{
High Directivity Microstrip Coupler with Single Slot of Unequal Length for GSM Dual Band
}

\author{
Maheswari Shanmugam \\ Research Scholar, Sathyabama University \\ Chennai, India \\ Email-maheswarisp@yahoo.co.in
}

\author{
Dr.T.Jayanthy \\ Panimalar Institute of Technology \\ Chennai, India \\ Email-jayanthymd@rediffmail.com
}

\begin{abstract}
In this paper a simple design procedure is used with accurate formulation. It comprises a complete design of symmetrical two-line Microstrip directional coupler including physical length at the desired operational frequency. The design procedure doesn't require the prior knowledge of the physical geometry of the coupler and requires only the information of the port impedances, coupling and operational frequency. To improve the directivity, the microstrip coupler was designed by a new approach for phase velocities compensation, which utilizes a coupled-Microstrip with a single slot of unequal length on its inner edges. Using this new design, a 15-dB coupler is designed and a high directivity of $34 \mathrm{~dB}$ or more is obtained over a considerably wide bandwidth for GSM dual band applications. The validity of the design concept is confirmed by emsimulations.
\end{abstract}

Index Terms - Microstrip, directional coupler, frequency.

\section{INTRODUCTION}

The Microstrip directional couplers are widely used in microwave applications because of the several advantages they have, i.e., manufacturability, repeatability, low cost, etc. The directional coupler is used to check and verify the power, frequency and antenna reflection of a signal at transmission stations for mobile communication. The performance requirements of directional couplers are a strong coupling to reduce the effect on the transmitted power and high directivity to suppress the interference of the reflected signal and reduce the errors in communication. However conventional architecture have a directivity of only $20 \mathrm{~dB}$, and there have been difficulties to achieve the higher directivity of $30 \mathrm{~dB}$ suitable for GSM dual band.

The existing design procedure depends on the knowledge of physical geometry of the directional coupler, i.e., design charts are used for the physical parameter versus the even and odd mode impedances. However designer only know the required coupling level, the port impedances that the directional coupler will be connected to, and operational frequency, initially. Since designers have no prior knowledge of physical dimensions for the directional couplers that will be designed, following the existing design methods can be quite cumbersome. However, their directivity somewhat poorer due to odd and even-mode wavelengths. For this reason, various techniques for improving the directivity have been proposed [1]-[5]. However, some of these techniques need complicated structures or substrates with specified physical constants, and/or the bandwidth is limited. Among them, the wiggling and slotting techniques are marked by broadband phase-velocity-compensation achieved by only a modification of patterning of the coupled-line section. The idea is based on the fact that the wiggly or slotting structure raises the odd mode inductance more strongly than that of the even mode due to the different current distributions between both modes.

In this paper a simple design procedure is used with accurate formulation [7]. It comprises a complete design of symmetrical two-line Microstrip directional coupler including physical length at the desired operational frequency. This design procedure requires the knowledge of the port termination impedances, coupling and the operational frequency. To improve the directivity, the microstrip coupler was designed by a new approach for phase velocities compensation [6], which utilizes a coupled-Microstrip with a single slot on its inner edges. The features of this coupler are an entirely planar structure similar to the wiggly types, realization of tighter coupling than slotting type, and directivity improvement over a broad bandwidth for GSM dual band $(900 \mathrm{MHz} \& 1800 \mathrm{MHz})$. The simulation was done using SONNET software and the values are presented for Rogers R03210 material for different coupling values.

\section{DESIGN OF MiCROSTRIP COUPLER}

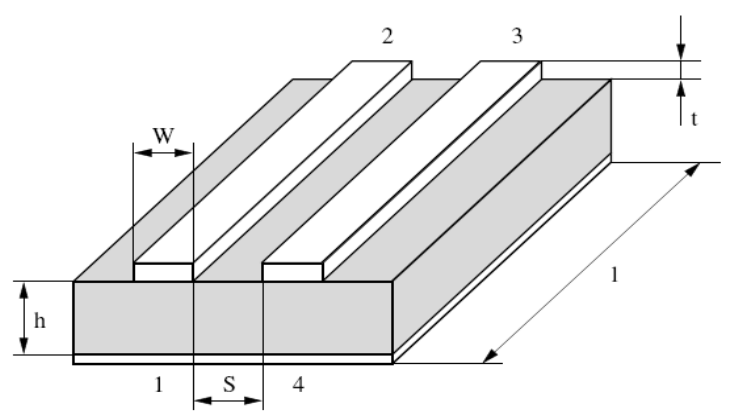

Fig. 1 Geometry of the microstrip coupler

The geometry of the Microstrip directional coupler is shown in Figure 1. As it is outlined in the introduction section, we assume that port impedance $\mathrm{Z}_{\mathrm{o}}$, coupling $(\mathrm{dB})$ and, the operational frequency are known parameters at 
beginning of the design. Based on the known parameters, the proposed design procedure has the following steps.

\section{Step 1 - Find Even and odd Mode Impedances}

The even and odd impedances, Zoe and Zoo, of the microstrip coupler given in Fig. 1 can be found as

$$
\begin{aligned}
& Z_{o e}=Z_{o} \sqrt{\frac{1+c}{1-c}} \\
& Z_{o o}=Z_{o} \sqrt{\frac{1-c}{1+c}}
\end{aligned}
$$

Where $\mathrm{c}$ is the coupling requirement and given in $\mathrm{dB}$.

\section{Step 2 - Find Physical Dimensions s/h and $w / h$}

The physical dimensions of the coupler are found as follows

$$
\begin{gathered}
\frac{w}{h}=\frac{8 e^{A}}{e^{2 A}-2} \text { for } \mathrm{w} / \mathrm{h}<2 \\
A=\frac{Z_{o}}{60} \sqrt{\frac{\varepsilon_{r}+1}{2}}+\frac{\varepsilon_{r}-1}{\varepsilon_{r}+1}\left(0.23+\frac{0.11}{\varepsilon_{r}}\right)
\end{gathered}
$$

$(\mathrm{w} / \mathrm{h})$ se and $(\mathrm{w} / \mathrm{h})$ so are the shape ratios for the equivalent single case corresponding to even mode and odd mode geometry respectively and are found as

$$
\begin{gathered}
(w / h)_{s e}=\left.(w / h)\right|_{Z_{\text {ose }}} \\
(w / h)_{\text {so }}=\left.(w / h)\right|_{Z_{\text {oso }}}
\end{gathered}
$$

Where $Z_{\text {ose }}$ and $Z_{\text {oso }}$ are the characteristic impedance for the single Microstrip shape ratios $(\mathrm{w} / \mathrm{h})_{\mathrm{se}}$ and $(\mathrm{w} / \mathrm{h})_{\mathrm{so}}$ respectively. They are found as

$$
\begin{gathered}
Z_{\text {ose }}=\frac{Z_{o e}}{2} \\
Z_{\text {oso }}=\frac{Z_{o o}}{2}
\end{gathered}
$$

Then the spacing ratio $\mathrm{s} / \mathrm{h}$ can be found as

$$
\frac{s}{h}=\frac{2}{\pi} \cosh ^{-1}\left[\frac{\cosh \left[\frac{\pi}{2}\left(\frac{w}{h}\right)_{s e}\right]+\cosh \left[\frac{\pi}{2}\left(\frac{w}{h}\right)_{s o}\right]-2}{\cosh \left[\frac{\pi}{2}\left(\frac{w}{h}\right)_{s o}\right]-\cosh \left[\frac{\pi}{2}\left(\frac{w}{h}\right)_{s e}\right]}\right]
$$

When the spacing ratio, s/h for the coupled lines is found, we can proceed to find the shape ratio $\mathrm{w} / \mathrm{h}$ for the coupled lines. The shape ratio for the coupled lines can now be found using

$$
\begin{gathered}
\left(\frac{w}{h}\right)=\frac{1}{\pi} \cosh ^{-1}(d)-\frac{1}{2}\left(\frac{s}{h}\right) \\
d=\frac{\cosh \left[\frac{\pi}{2}\left(\frac{w}{h}\right)_{s e}\right](g+1)+g-1}{2} \\
g=\cosh \left[\left(\frac{\pi}{2}\right)\left(\frac{s}{h}\right)\right]
\end{gathered}
$$

\section{Step 3 - Find Physical Length of the Directional Coupler}

The physical length of the directional coupler can be found using

$$
l=\frac{\lambda}{4}=\frac{c}{4 f \sqrt{\varepsilon_{e f f}}}
$$

Where, $\mathrm{c}=3^{*} 10^{8} \mathrm{~m} / \mathrm{sec}$ and $\mathrm{f}$ is operational frequency in $\mathrm{Hz}$ and Eeff is the effective permittivity constant of the coupled structure.

\section{NUMERICAL RESULTS}

The numerical results are obtained using the analytical method described above for Rogers R03210 material with $\varepsilon_{\mathrm{r}}=10.2$. Table 1 gives the complete design parameter including the length of the directional coupler for the given coupling level at the operational frequency. $\mathrm{Z}_{\mathrm{o}}$ is assumed to be equal to the port impedances and taken as 50 and $\mathrm{f}$ is the operational frequency and given in $\mathrm{GHz}$

TABLE 1

\begin{tabular}{|c|c|c|c|c|}
\hline $\begin{array}{c}\text { Coupling } \\
(\mathbf{d B})\end{array}$ & $\mathbf{w} / \mathbf{h}$ & $\mathbf{s} / \mathbf{h}$ & $\boldsymbol{l}(\mathbf{m m})$ & $\mathbf{f}(\mathbf{G H z})$ \\
\hline-10 & 0.8588 & 0.1189 & 19.1 & 1.5 \\
\hline-15 & 0.9981 & 0.3699 & 19.1 & 1.5 \\
\hline-20 & 1.0465 & 0.6967 & 19.1 & 1.5 \\
\hline
\end{tabular}

IV. SiMULATION RESULTS

A $15 \mathrm{~dB}$ conventional microstrip coupler is designed with design values are $\mathrm{w}=0.5 \mathrm{~mm}, \mathrm{~s}=0.2 \mathrm{~mm}, \mathrm{~h}=0.5 \mathrm{~mm}, l=19 \mathrm{~mm}$ with $\varepsilon_{\mathrm{r}}=10.2$ at $1.5 \mathrm{GHz}$. The simulation was done using SONNET software and the simulated structure is shown in Figure 2 and the simulation results were shown in Figure 3. 


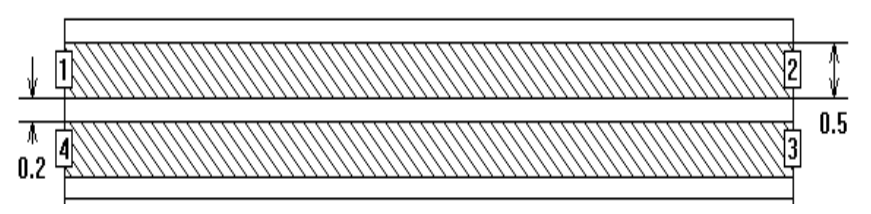

Fig. 2. Structure of simulated conventional $15 \mathrm{~dB}$ microstrip coupler

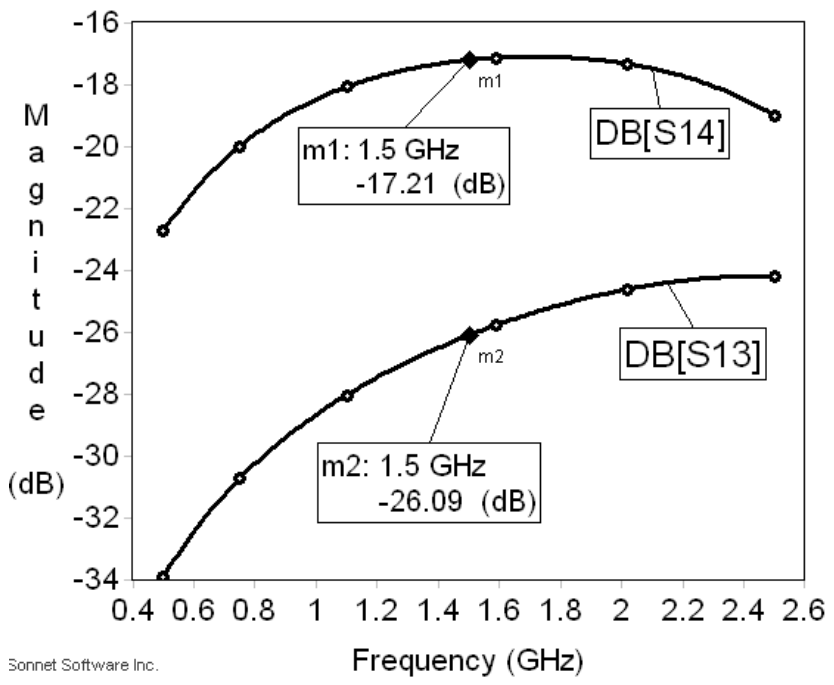

Fig. 3. Simulation results of a $15 \mathrm{~dB}$ conventional microstrip coupler

The simulation result shows that for a conventional microstrip directional coupler the isolation was $26.09 \mathrm{~dB}$ and coupling was $17.21 \mathrm{~dB}$. The directivity can be calculated as isolation - coupling. Therefore the directivity obtained was only $9 \mathrm{~dB}$. It can be increased up to $34 \mathrm{~dB}$ or more by using a single slot of unequal length on its inner edge as shown in Figure 4.

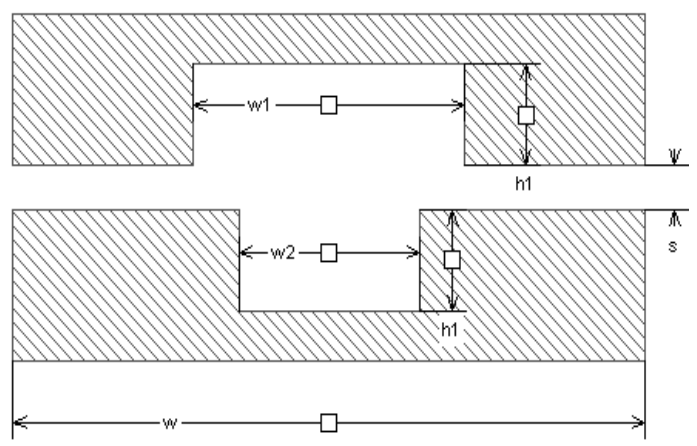

Fig. 4. Structure of microstrip coupler with single slot of unequal length

\section{SIMULATION RESULTS OF MICROSTRIP COUPLER WITH SINGLE SLOT OF UNEQUAL LENGTH}

A $15 \mathrm{~dB}$ microstrip coupler is designed with a single slot of unequal length on its inner edges with design values are $\mathrm{w}=0.5 \mathrm{~mm}, \mathrm{~s}=0.2 \mathrm{~mm}, \mathrm{~h}=0.5 \mathrm{~mm}, l=19 \mathrm{~mm}, \mathrm{w} 1=6.32 \mathrm{~mm}$, $\mathrm{w} 2=5.32 \mathrm{~mm}, \mathrm{~h} 1=0.2 \mathrm{~mm}$, with $\varepsilon_{\mathrm{r}}=10.2$ at $1.5 \mathrm{GHz}$. The position of the slot is selected approximately at the centre of the coupler. The simulation was done using SONNET software and the results are shown in Figure 5.

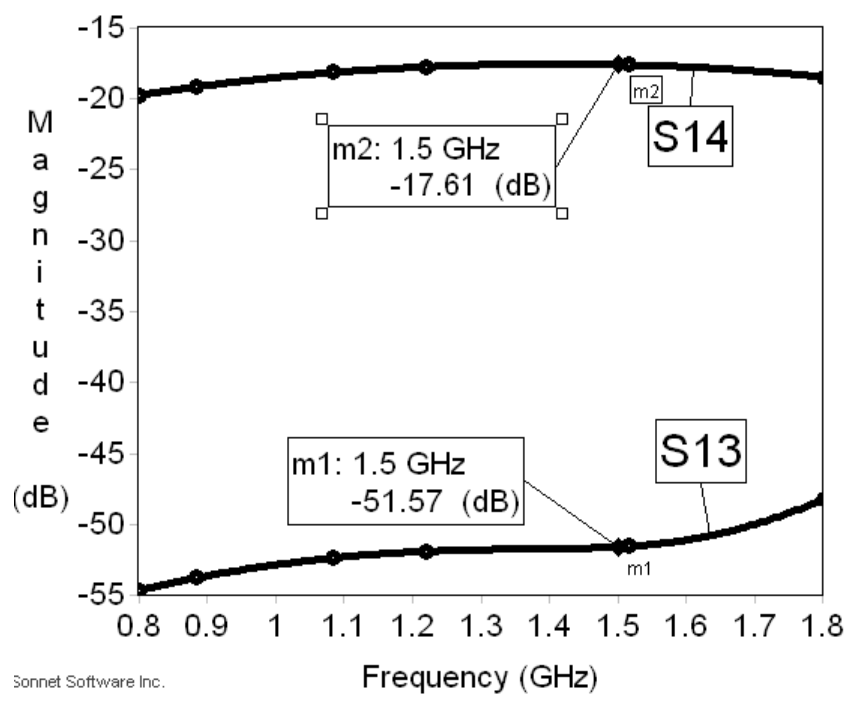

Fig. 5. Simulation results of microstrip coupler with single slot of unequal length

The simulation results shows that for a microstrip coupler with single slot of unequal length the isolation was $51.57 \mathrm{~dB}$ and coupling was $17.61 \mathrm{~dB}$. The directivity can be calculated as isolation - coupling. Therefore the directivity obtained was $34 \mathrm{~dB}$. Thus a slot of unequal length on the inner edges of the coupler is used to improve the directivity using phase velocity compensation technique.

\section{CONCLUSION}

In this paper, a complete design of Microstrip directional coupler is presented by introducing a simple design procedure. This procedure requires the knowledge of port termination impedance, coupling and operational frequency. And the directivity the microstrip coupler was improved using phase velocity compensation up to $34 \mathrm{~dB}$ or more over a wide bandwidth by a new design approach, which utilizes a microstrip coupler with a single slot of unequal length on its inner edges. The designed microstrip coupler can be used for GSM dual band $(900 \mathrm{MHz} \& 1800 \mathrm{MHz})$ applications. The design concept was verified using em simulations.

\section{REFERENCES}

[1]. R. Phromloungsri, V. Chamnanphrai, and M. Chongcheawchamnan, "Design high-directivity parallel-coupled lines using quadrupled inductive- compensated technique," in Asia-Pacific Microw. Conf. Dig., 2006, pp. 1380-1383.

[2]. Seungku Lee and Yongshik Lee, "A Design Method for Microstrip Directional Couplers Loaded with Shunt Inductors for Directivity Enhancement", IEEE Trans. Microwave Theory \& Tech., vol.58, No.4, pp. 994-1002, April 2010.

[3]. J.-L. Chen, S.-F. Chang, and C.-T. Wu, "A high-directivity microstrip directional coupler with feedback compensation," in 2002 IEEE MTTS Int. Microwave Symp. Dig., vol. 1, June 2002, pp. 101-104.

[4]. Sheng-Fuh Chang, Jia-Liang Chen, Yng-Huey Jeng, and Chain-Tin Wu, "New High-Directivity Coupler Design with Coupled Spurlines", 
IEEE Microwave and Wireless Components Letters, VOL. 14, NO. 2, pp.65-67, February 2004

[5]. I. Ohta, T. Kawai, T. Fujii, and Y. Kokubo, "Directivity improvement of microstrip coupled line couplers based on equivalent admittance approach," 2003 IEEE MTT-S Int'l Microwave Symposium Digest, vol.1, pp.43-46, June2003.

[6]. Takao Fujii, Yoshihiro Kokubo, and Isao Ohta, "High Directivity Quarter-Wave Microstrip Couplers with Periodic Floating-Conductors on Coupled Edges". Proceedings of the 36th European Microwave Conference, pp.32-35, Sept. 2006.

[7]. T.C Edwards \& M.B.Steer, Foundation of Interconnect and Microstrip Design (third edition), John Wiley \& Sons Ltd, 2000. 